\title{
1 In vitro Cchemo-protective effect of bioactive peptide lunasin against 2 oxidative stress in human HepG2 cells
}

3

4 Samuel Fernández-Tomé ${ }^{1}$, Sonia Ramos $^{2}$, Isabel Cordero-Herrera ${ }^{2}$, Isidra Recio ${ }^{1}$, Luis

5 Goya $^{2 *}$ and Blanca Hernández-Ledesma ${ }^{1 *}$

6

7

$8{ }^{1}$ Departamento de Bioactividad y Análisis de Alimentos. Instituto de Investigación en

9 Ciencias de la Alimentación (CIAL, CSIC-UAM, CEI UAM+CSIC). Nicolás Cabrera, 9.

1028049 Madrid, Spain

11

$12{ }^{2}$ Departamento de Metabolismo y Nutrición. Instituto de Ciencia y Tecnología de Alimentos

13 y Nutrición ICTAN (CSIC); José Antonio Novais, 10. 28040 Madrid, Spain

14

15 Running title: Lunasin protects HepG2 from oxidative stress

16

17 * Corresponding autor: Blanca Hernández-Ledesma, Departamento de Bioactividad y

18 Análisis de Alimentos. Instituto de Investigación en Ciencias de la Alimentación (CIAL,

19 CSIC-UAM, CEI UAM+CSIC). Nicolás Cabrera, 9. 28049 Madrid, Spain. Phone:

20 +34910017970. Fax: +34 910017905. e-mail: $\underline{\text { b.hernandez@csic.es }}$

$21 *$ Co-Corresponding autor: Luis Goya, Departamento de Metabolismo y Nutrición. Instituto

22 de Ciencia y Tecnología de Alimentos y Nutrición ICTAN (CSIC); José Antonio Novais, 10;

2328040 Madrid, Spain. Phone: +34915445607. Fax: +34915493627. e-mail:

24 luisgoya@ictan.csic.es 


\section{ABSTRACT}

28 Lunasin is a peptide with proven properties against cancer and cardiovascular diseases. Relevant amounts of lunasin have been found in liver of rats fed lunasin-enriched diets, indicating its potential bioactive effect in this tissue. This study investigated the stability of

31 lunasin in human liver HepG2 cells, and its chemoprotective effect against oxidative stress

induced by tert-butylhydroperoxide. Cell viability and biomarkers of redox status were evaluated. Pre-treatment of cells with lunasin $(0.5-10 \mu \mathrm{M})$ significantly prevented the increased reactive oxygen species (ROS) generation (122\% compared to $190 \%$ in stressed $\underline{\text { cells) }}$, and glutathione peroxidase and catalase activities, as well as the depletion of reduced glutathione. By restraining ROS overproduction, lunasin evoked a decline in carbonyl groups, and a significant recovery from cell death by apoptosis. These findings suggest that lunasin, at physiological concentrations, might confer a significant chemoprotection against oxidative stress-associated liver disorders. In addition, fragments released after hydrolysis of lunasin by cell enzymes might contribute on the observed antioxidant effects.

Keywords: antioxidant defences, biomarkers for oxidative stress, dietary antioxidants, peptide lunasin 


\section{INTRODUCTION}

Cells are naturally provided with an extensive array of protective enzymatic and nonenzymatic antioxidants that counteract the potentially injurious oxidizing agents. But even this multifunctional protective system cannot completely prevent the deleterious effects of reactive oxygen species (ROS), and consequently, molecules damaged by oxidation accumulate in cells. Large amounts of ROS have been shown to participate in the pathogenesis of several human degenerative diseases, including inflammation, cardiovascular and neurodegenerative disorders, and cancer (Ramos, 2008). Restoration or activation of improperly working or repressed antioxidant machinery as well as suppression of abnormally amplified inflammatory signalling can provide important strategies for chemoprevention. Therefore, determination of anti-inflammatory and/or antioxidant properties has been proposed as a good indicator for screening anti-cancer agents (Federico, Morgillo, Tuccillo, Clardiello, \& Loguercio, 2007).

There is substantial evidence that antioxidant food components have a protective role against oxidative stress-induced atherosclerosis, degenerative and age-related diseases, cancer and aging. ${ }^{1}$ Food-derived peptides are promising natural antioxidants without marked adverse effects. In addition to their potential as safer alternatives to synthetic antioxidants used to avoid or retard oxidation reactions in foods, antioxidant peptides can also act reducing the risk of numerous oxidative stress-associated disorders (Meisel, 2004). Lunasin is a 43-amino acid peptide identified in soybean and other seeds and plants which chemopreventive properties have been recently reviewed (Hernández-Ledesma, Hsieh, \& de Lumen, 2013). This peptide has demonstrated, by using cell cultures and animal models, to act as anticarcinogenic agent against skin, prostate, colon, and breast cancer (Hernández-Ledesma, de Lumen, \& Hsieh, 2013). Recently, lunasin has been commercialized in the US by its benefits on cardiovascular system through reduction of low density lipoprotein cholesterol concentration (Gálvez, 2012). 
Moreover, its promising anti-inflammatory and antioxidant activities reported in the recent years might contribute on lunasin chemoprotective action. Lunasin has been shown to inhibit inflammation in cultured RAW 264.7 macrophages through suppression of nuclear factor (NF)-אB pathway (González de Mejia, \& Dia, 2009; Hernández-Ledesma, Hsieh, \& de Lumen, 2009a; Cam, Sivaguru, \& González de Mejia, 2013). Additionally, in vitro assays have revealed the ability of this peptide to scavenge peroxyl radicals, and to block Fenton reaction by chelating iron ferrous ions, protecting DNA from oxidative damage (HernándezLedesma et al., 2009a; Jeong, de Lumen, \& Jeong, 2010; García-Nebot, Recio, \& HernándezLedesma, 2014).

Studies on bioavailability carried out in mice and rats have demonstrated that, after its oral ingestion, lunasin appears in an intact and active form in different organs and tissues, such as blood, liver, and kidney, among others (Jeong, Lee, Jeong, Park, Cheong, \& de Lumen, 2009; Hsieh, Hernández-Ledesma, Jeong, Park, \& de Lumen, 2010). In humans, presence of lunasin has been also reported in plasma, indicating that this peptide might reach different target tissues, and exert its biological activity (Dia, Torres, de Lumen, Erdman, \& González de Mejia, 2009).

The liver is particularly susceptible to toxic and oxidative insults since the portal vein brings blood to this organ after intestinal absorption. Therefore, studies dealing with the effects of chemopreventive compounds at a cellular level in cultured hepatic cells are essential. Human HepG2, a well differentiated transformed cell line, is a reliable model for cultured hepatocyte-type cells used for biochemical, pharmacological and nutritional studies since it retain hepatocyte morphology and most of its functionality in culture (Alía, Ramos, Mateos, Bravo, \& Goya, 2006; Mateos, Goya, \& Bravo, 2006).

The aims of the study were to evaluate the stability of lunasin in human liver HepG2 cells as a model for cultured hepatocytes, and to investigate the potential chemo-protective effect 
of this peptide against oxidative stress chemically induced by a potent pro-oxidant, tert-butyl hydroperoxide $(t-\mathrm{BOOH})$. Cell integrity and several biomarkers of oxidative damage were evaluated to estimate the effect of lunasin on cell survival and on the response of the antioxidant defence systems of HepG2 cells to $t$-BOOH.

\section{MATERIALS AND METHODS}

\subsection{Reagents}

Peptide lunasin (>95\% of purity) was synthesized by Chengdu KaiJie Biopharm Co., Ltd (Chengdu, Sichuan, P. R. China). $t$-BOOH, glutathione reductase, reduced glutathione (GSH), nicotine adenine dinucleotide phosphate reduced salt (NADPH), o-phthalaldehyde (OPT), dichlorofluorescin (DCFH), dinitrophenylhydrazine (DNPH), trifluoroacetic acid (TFA), ethylenediaminetetraacetic acid (EDTA), $\beta$-mercaptoethanol, gentamicin, penicillin G, streptomycin, Triton-X100, 4-(2-hydroxyethyl)piperazine-1-ethanesulfonic acid (HEPES) and dithiothreitol (DTT) were purchased from Sigma Chemical Co. (Madrid, Spain). Sodium dodecyl sulphate (SDS) was from Panreac Química (Madrid, Spain). N-acetyl-Asp-Glu-ValAsp-7-amino-4-methylcoumarin (Ac-DEVD-AMC) was from BD Pharmigen (Madrid, Spain). Bradford reagent was from BioRad Laboratories S.A. (Madrid, Spain). The rest of chemicals used were of HPLC grade.

\subsection{Cell culture}

Human HepG2 cells were grown in a humidified incubator containing 5\% $\mathrm{CO}_{2}$ and $95 \%$ air at $37^{\circ} \mathrm{C}$. They were grown in Dulbecco's Modified Eagle Medium (DMEM)-F12 medium from Biowhitaker (Lonza, Madrid, Spain), supplemented with 2.5\% (v/v) Biowhitaker foetal bovine serum (FBS) and $50 \mathrm{mg} / \mathrm{L}$ of each of the following antibiotics: gentamicin, penicillin 
$120 \mathrm{G}$, and streptomycin. Cells were changed to FBS-free medium the day before the assay

121 (Mateos et al., 2006).

\subsection{Cell treatment conditions}

Cells were incubated for $20 \mathrm{~h}$ with peptide lunasin dissolved in FBS-free DMEM-F12 at final concentrations ranging from 0.5 to $10 \mu \mathrm{M}$. To evaluate both direct and protective effects against oxidative stress, the incubation period was followed by a $3 \mathrm{~h}$ treatment with culture medium (direct effect) or oxidant chemical $t$-BOOH $(400 \mu \mathrm{M})$. Crystal violet $(\mathrm{CV})$ staining, GSH concentration, ROS generation and glutathione peroxidase (GPx) and catalase (CAT) activities were evaluated in both direct and protective experiments. Besides, the protective effect of lunasin against $t$-BOOH-induced oxidative damage to proteins and apoptotic cellular signals was evaluated by carbonyl groups and caspase-3 assays, respectively.

\subsubsection{Crystal violet assay}

134 Cell viability was evaluated following the CV assay described by Granado-Serrano and HepG2 cells were seeded in 96-well plates $\left(1 \times 10^{4}\right.$ cells per well $)$ and incubated overnight. Then, cells were treated with lunasin for $20 \mathrm{~h}$ as described above, washed with PBS, and

138 incubated with $\mathrm{CV}(0.2 \%$ in ethanol) for $20 \mathrm{~min}$ at room temperature. Finally, cell lysis was carried out with $1 \% \mathrm{SDS}$, and the absorbance was read at $570 \mathrm{~nm}$ in a microplate reader

140 (FL600, Bio-Tek, Winooski, VT, USA). Results were pooled from different plates to obtain 141 average of $n=12$, and presented as percentage of viable cells compared to control, considered 142 as $100 \%$. 


\subsubsection{Morphological analysis}

HepG2 cells were exposed to increasing concentrations $(0.5-10 \mu \mathrm{M})$ of lunasin for $20 \mathrm{~h}$, then treated with DMEM (controls) or DMEM supplemented with $t$-BOOH for $3 \mathrm{~h}$, and cell images were taken using an inverted phase contrast microscope at $20 \times$ magnification.

\subsubsection{Determination of intracellular ROS levels}

Intracellular ROS levels were quantified following the method described by Alía and coworkers, using DCFH as fluorescent probe (Alía, Ramos, Mateos, Bravo, \& Goya, 2005). HepG2 were cultured in 24-wells multiwell plates $\left(2 \times 10^{5}\right.$ cells per well), incubated overnight, and then, treated with lunasin as described above. After $19.5 \mathrm{~h}$ incubation with the peptide, a solution of DCFH was added to each well (5 $\mu \mathrm{M}$ final concentration), and cells were incubated in the dark for $30 \mathrm{~min}$ at $37^{\circ} \mathrm{C}$. Afterwards, cells were washed with PBS, incubated with culture medium (direct effects), or subjected to chemical-induced oxidative stress with $t$-BOOH (protective effects). The production of intracellular ROS was followed over $3 \mathrm{~h}$ measuring the fluorescence intensity at $\lambda_{\text {excitation }}$ and $\lambda_{\text {emission }}$ of $485 \mathrm{~nm}$ and $530 \mathrm{~nm}$, respectively, in a microplate reader (FL600, Bio-Tek). The results were pooled from different plates to obtain average of $n=8$, and expressed as percentage of the control (cells in a basal state), considered as $100 \%$.

\subsubsection{Quantification of concentration of GSH and determination of GPx and CAT activity}

Cells were seeded onto 100-mm Petri dishes, incubated overnight, treated with lunasin (for both direct and protective assays), exposed to $t$-BOOH (for protective assays), and then, collected following the methodology described by Quéguineur and co-workers (Quéguineur, Goya, Ramos, Martín, Mateos, \& Bravo, 2012). The obtained supernatants, corresponding to the cellular content of HepG2 cells, were subjected to the determination of the concentration 
of GSH and the activity of GPx and CAT enzymes. The content of GSH was evaluated by a

171 fluorometric assay as previously described (Quéguineur et al., 2012). Briefly, $50 \mu \mathrm{L}$ of each

172 sample were transferred in triplicate to a 96-multiwell plate, and the reaction mixture

173 containing $15 \mu \mathrm{L}$ of $1 \mathrm{M} \mathrm{NaOH}, 175 \mu \mathrm{L}$ of PBS/EDTA, and $10 \mu \mathrm{L}$ of a solution of OPT (10

$174 \mathrm{mg} / \mathrm{mL})$ was added. After $20 \mathrm{~min}$ incubation, the fluorescence was read $\left(\lambda_{\text {excitation }} / \lambda_{\text {emission }}=\right.$

$175340 / 460 \mathrm{~nm}$ ) in a microplate reader (FL600, Bio-Tek). Results were pooled from different

176 plates to obtain average of $n=6$, and interpreted considering those of a standard GSH curve

177 similarly prepared within each of the experiments run.

178 GPx catalyses the oxidation of GSH to oxidized glutathione, using $t$-BOOH as a substrate,

179 reaction coupled to the decomposition of NADPH to $\beta$-nicotinamide adenine dinucleotide by

180 glutathione reductase. Thus, disappearance of NADPH reliably estimates GPx activity, which

181 can be measured by following the decrease in absorbance at $340 \mathrm{~nm}$ (Alía et al., 2006). CAT

182 activity was determined by following the breakdown of the peroxide $\mathrm{H}_{2} \mathrm{O}_{2}$ to $\mathrm{H}_{2} \mathrm{O}$, monitored

183 as a decrease in absorbance at $240 \mathrm{~nm}$ (Granado-Serrano et al., 2007). Results for both GPx

184 and CAT activities were pooled from different plates to obtain average of $n=6$, and 4 ,

185 respectively, and referred to the total protein concentration of the cytosolic samples, measured

186 by the Bradford reagent (Bio-Rad).

187

\subsubsection{Evaluation of carbonyl groups}

189 Oxidative damage to proteins by reactive species, particularly ROS, was evaluated by

190 measuring the content of carbonyl groups in cell supernatants according to the method of

191 Richert and co-workers (Richert, Wehr, Stadtman, \& Levine, 2002). Absorbance was

192 measured at $360 \mathrm{~nm}$, and carbonyl content results (experiments run to obtain an average of $n$

$193=4$ ) were expressed as nmol of carbonyl groups per mg of total protein, using an extinction

194 coefficient of $22000 \mathrm{nmol} / \mathrm{L} / \mathrm{cm}$. 


\subsubsection{Determination of caspase-3 activity}

196 Caspase-3 activity was measured according to the fluorometric assay previously described

197 (Herrera et al., 2001). After treatment with lunasin for $20 \mathrm{~h}$ and chemical induction with $t$ -

$198 \mathrm{BOOH}$ for $3 \mathrm{~h}$, cells were collected, and lysed in a buffer containing $5 \mathrm{mM}$ Tris, $20 \mathrm{mM}$

199 EDTA, and $0.5 \%$ Triton-X100. Then, the reaction mix containing $30 \mu \mathrm{g}$ cell protein, $20 \mathrm{mM}$

200 HEPES, 10\% glycerol, $2 \mathrm{mM}$ DTT, and $20 \mu \mathrm{M}$ Ac-DEVD-AMC was incubated in the dark

201 for $2 \mathrm{~h}$. Fluorescence was measured at $\lambda_{\text {excitation }}$ and $\lambda_{\text {emission }}$ of $380 \mathrm{~nm}$ and $440 \mathrm{~nm}$, 202 respectively, in a microplate reader (FL600, Bio-Tek), and enzymatic activity results 203 (experiments run to obtain an average of $n=4$ ) were expressed as units of caspase-3 per $\mu \mathrm{g}$ of 204 total protein.

\subsection{Stability of lunasin}

HepG2 cells were plated in $60 \mathrm{~mm}$-diameter plates at a density of $1.5 \times 10^{6}$ cells per plate, and incubated at $37^{\circ} \mathrm{C}$ overnight. Then, cells were treated with $10 \mu \mathrm{M}$ lunasin dissolved in FBS free DMEM-F12, and incubated at $37^{\circ} \mathrm{C}$ for $20 \mathrm{~h}$, taking aliquots of the medium at 0,2 , 6, 12, and $20 \mathrm{~h}$ of incubation. These aliquots were subjected to liquid chromatography (HPLC) coupled to tandem mass spectrometry (HPLC-MS/MS) on an Agilent 1100 HPLC ion trap (Bruker Daltonik GmbH, Bremen, Germany), and equipped with an electrospray 214 ionization source as previously described (Contreras, Gómez-Sala, Martín-Álvarez, Amigo, 215 Ramos, \& Recio, 2010). The column used was a Mediterranea Sea 18 (150 x $2.1 \mathrm{~mm}$, 216 Teknokroma, Barcelona, Spain), the injection volume was $50 \mu \mathrm{L}$, and the flow was set at 0.2 $217 \mathrm{~mL} / \mathrm{min}$. Peptides were eluted with a linear gradient of solvent B (acetonitrile:TFA 1000:0.27 $218 \mathrm{v} / \mathrm{v}$ ) in A (water:TFA 1000:0.37 v/v) going from 0\% to $45 \%$ in $130 \mathrm{~min}$. Data obtained were 219 processed and transformed to spectra representing mass values using the Data Analysis 
program (version 4.0, Bruker Daltonik). To process the MS/MS spectra and to perform 221 peptide sequencing BioTools (version 3.1, Bruker Daltonik) was used.

\subsection{Statistics}

Data were analyzed by a one-way ANOVA followed by the Bonferroni Multiple Comparison test, and expressed as the mean \pm standard variation (SD). GraphPad Prism 5.0 software (San Diego, CA, USA) was used to perform statistical analyses. Differences with a $P$ value $<0.05(*, \#), P$ value $<0.01(* *, \# \#)$ or $P$ value $<0.001(* * * \# \#)$ were considered significant.

\section{RESULTS AND DISCUSSION}

\subsection{Chemoprotective effects of lunasin on cell viability and redox status}

In order to evaluate the effect of lunasin at physiological level, in the present study, a range of concentrations between 0.5 to $10 \mu \mathrm{M}$ was selected. Previous studies on lunasin's

234 bioavailability have demonstrated that, because of the protection against gastric and 235 pancreatic enzymes exerted by naturally occurring protease inhibitors such as the Bowman236 Birk inhibitor (BBI), a high percentage of daily ingested peptide remains intact during its 237 passage through gastrointestinal tract, reaching target organs and tissues in an active form 238 (Hsieh et al., 2010). The presence of lunasin and BBI has been confirmed in different soybean 239 products, such as soymilk, tofu, soybean cake and fermented soybean products (Hernández240 Ledesma, Hsieh, \& de Lumen, 2009b). Daily consumption of $25 \mathrm{~g}$ of soy protein, 241 recommended by Food and Drug Administration (FDA) to reduce coronary disease (FDA, 242 1999), supplies lunasin in quantity ranged from $110 \mathrm{mg}(21.9 \mu \mathrm{mol})$ to $1760 \mathrm{mg}(350.2$ $243 \mu \mathrm{mol})$. Selected concentrations in our study were not far from reality since steady-state 244 concentrations of $99.3 \mu \mathrm{g} / \mathrm{g}$ tissue were isolated from liver of rats fed lunasin-enriched rye 
diets for 4 weeks, and lunasin extracted from those livers has been demonstrated to be active 246 (Jeong et al., 2009).

247 Before testing the chemo-protective effect of lunasin, it was important to evaluate the 248 effect of this peptide per se, in basal conditions, ensuring that no direct damage is caused to 249 the cell by the compound. Thus, the direct effect of lunasin on HepG2 cells viability was 250 evaluated. The CV assay, based on the growth rate reduction reflected by the colorimetric 251 determination of the stained cells, was used to determine the cell viability. As shown in 252 Figure 1A, treatment of HepG2 cells with lunasin for $20 \mathrm{~h}$ evoked no decreases in CV 253 staining, indicating that the concentrations selected for the study $(0.5-10 \mu \mathrm{M})$ did not damage 254 cell integrity during the period of incubation. Higher concentrations of lunasin were also 255 assessed, observing that the percentage of viable cells were not affected by $25 \mu \mathrm{M}$ lunasin $(111.20 \% \pm 4.80)$ and $50 \mu \mathrm{M}$ lunasin $(111.07 \% \pm 6.19)$ Because of its connection to the gastrointestinal tract and its unique metabolic activity, the liver is one of the main body targets of the toxicity of drugs, xenobiotics, environmental contaminants, as well as oxidative stress (Jaeschke, Gores, Cederbaum, Hinson, Pessayre, \& Lemasters, 2002). The cell damage caused by ROS and other reactive species plays a crucial role in the induction and progression of several liver diseases such as hepatocarcinoma, viral 262 and alcoholic hepatitis, and non-alcoholic steatosis. Consequently, there is an increasing 263 interest in new therapeutic agents protecting liver from such oxidative damage, with natural 264 antioxidants being considered one of the most effective alternatives (Vitaglione, Morisco, 265 Caporaso, \& Fogliano, 2004). $t$-BOOH, a short-chain analog of lipid peroxide, is often used to 266 induce acute oxidative stress in different in vitro and in vivo systems, and to evaluate the 267 protective effects of antioxidants (Mersch-Sundermann, Knasmuller, Wu, Darroudi, \& Kassie, 268 2004). In the case of hepatocytes, these cells metabolize $t$-BOOH to toxic peroxyl and alkoxyl 269 radicals, initiating peroxidation of macromolecules, and thus, affecting the cell integrity and 
leading to chemical-induced hepatic oxidative damage. Therefore, treatment of HepG2 cells

271 with $t-\mathrm{BOOH}$ is an excellent model of oxidative stress in cell culture systems (Alía et al., 272 2005). To evaluate whether lunasin protects HepG2 from oxidative stress induced by $t$ $273 \mathrm{BOOH}$, we first determined its effects on the cell viability. As shown in Figure 1A, the 274 percentage of viable cells in HepG2 induced by $400 \mu \mathrm{M} t$-BOOH was $67.5 \%$ (compared to 275 non-stressed cells), indicating that this chemical showed remarkable cytotoxicity $(P<0.001)$ 276 on these cells. However, incubation of the cells with $0.5-10 \mu \mathrm{M}$ lunasin for $20 \mathrm{~h}$, prior to 277 chemical oxidant treatment, significantly restored cell viability up to $99.8 \%(P<0.001)$, 278 although dose-dependent effects were not observed.

As shown in Figure 2A and 2B, HepG2 cells treated with $t$-BOOH showed reduction

in cell numbers and loss of cell-to-cell contact. These morphological changes in $t$-BOOHinduced HepG2 cells were attenuated by pre-treatment with lunasin at $0.5 \mu \mathrm{M}$ (Figure $2 \mathrm{C}$ ), and $5 \mu \mathrm{M}$ (Figure 2D).

As shown in Figure 2A, 2B, morphological changes in HepG2 cells due to the toxic effect of $\neq \mathrm{BOOH}$ were clearly visible. However, such changes were reduced by lunasin at $0.5 \mu \mathrm{M}$

(Figure 2C), and $5 \mu \mathrm{M}$ (Figure 2D).

to the reduction of oxidative stress, the intracellular ROS generation was evaluated in HepG2 exposed to $t-\mathrm{BOOH}$ with and without pre-treatment with lunasin for $20 \mathrm{~h}$. As shown in Figure 1B, the level of intracellular ROS in HepG2 cells treated with $t$-BOOH alone was $190.0 \%$ compared to the non-treated cells (considered as $100 \%$ ), indicating that $400 \mu \mathrm{M} t$-BOOH had

291 a strong effect on ROS generation. When the cells were pre-treated with lunasin, intracellular 292 ROS levels were significantly decreased up to $122 \%$ (compared to control) $(P<0.001)$, but no dose-dependent activity was observed. These results suggest that ROS generated during 294 the period of oxidative stress were more efficiently quenched in cells pre-treated $20 \mathrm{~h}$ with 
lunasin, which could be a first explanation for the reduced cell damage and death shown. The

296 intracellular ROS levels of non-stressed cells were also decreased by treatment with lunasin,

297 reaching $63.6 \%$ (compared to control cells) when $5 \mu \mathrm{M}$ lunasin was used (Figure 1B). These

298 findings confirm the ability of this peptide as an effective scavenger of ROS in cell cultures.

299 Previous studies have demonstrated that lunasin is a potent antioxidant in different in vitro 300 assays, including reducing power, and ABTS, peroxyl and superoxide radical scavenging 301 activity (Hernández-Ledesma et al., 2009a; Jeong et al., 2010; García-Nebot et al., 2014).

Lunasin at concentrations higher than $1 \mu \mathrm{M}$ significantly increased the cytosolic levels of

$\underline{\text { GSH }(P<0.05) \text { (Figure } 1 \mathrm{C}) . \text { GSH is a tripeptide found in all mammalian cells and considered }}$ $\underline{\text { the main non-enzymatic antioxidant defense within the cell. It appears in high concentration }}$ in the liver where plays a crucial role protecting against oxidative stress through elimination of toxic ROS, and mitigation of macromolecules peroxidation and cell injury (Mari, Morales,

Colell, García-Ruiz, \& Fernández-Checa, 2009). It is usually assumed that enhanced levels of $\underline{\text { GSH prepare the hepatocytes against a potential oxidative insult, whereas its depletion }}$ reflects an intracellular oxidation state (Alía et al., 2005). The effect of lunasin on GSH levels, together the decreased ROS generation, reflects a diminished intracellular oxidation which could be expected to place the cell in favourable conditions to face a potential oxidative insult. In addition to its effect as inducer of ROS generation, $t \mathrm{BOOH}$ also provokes GSH depletion (Goya, Mateos, \& Bravo, 2007). GSH is a tripeptide found in all mammalian cells and considered the main non enzymatic antioxidant defense within the cell. It appears in high eoncentration in the liver where plays a crucial role protecting against oxidative stress through elimination of toxic ROS, and mitigation of macromelecules peroxidation and cell injury (Mari, Morales, Colell, García Ruiz, \& Fernández Checa, 2009). It is usually assumed that its depletion reflects an intracellular oxidation state (Alía et al., 2005). Lunasin at 
eoncentrations higher than $1 \mu \mathrm{M}$ significantly increased the cytosolic levels of GSH $(P<$

0.05) (Figure 1C). This result, together the decreased ROS generation, reflects a diminished intracellular oxidation which could be expected to place the cell in favourable conditions to face a potential oxidative insult. As it is demonstrated in the present study, tTreatment of

324 HepG2 cells with $t$-BOOH induced a significant decrease in the concentration of GSH $(P<$ 0.001), as it was previously demonstrated (Goya, Mateos, \& Bravo, 2007). However, this depletion of the GSH store was partly prevented by pre-treatment with lunasin (Figure 1C). These findings indicate that increased levels of GSH in the lunasin-treated cells before exposure to the oxidative damage greatly helped to prevent the dramatic depletion of

329 intracellular GSH during the oxidative stress, an effect of lunasin that had not been reported 330 previously. Maintaining GSH concentration above a critical threshold while facing a stressful 331 situation represents an enormous advantage for cell survival.

\subsection{Influence of lunasin on antioxidant enzymes activity}

334 In order to investigate whether the antioxidant properties of lunasin are related to the induction of the antioxidant enzymes activity, HepG2 cells were treated with this peptide, and the activity of enzymes GPx and CAT was measured. $\underline{\text { In non-stressed HepG2 cells, lunasin }}$ did not provoke any change in the activity of GPx and CAT (data not shown). These results indicate that in spite of the direct effects of lunasin on ROS levels and GSH content, the defence enzymatic system in the cells was balanced. The increase in the activity of GPx and

340 CAT observed after exposure to $t-\mathrm{BOOH}$ (Figure 3A and 3B), clearly indicates a positive response of the cell defense system to face the increasing generation of ROS evoked by the oxidative insult (Alía et al., 2006; Goya, Martín, Ramos, Mateos, \& Bravo, 2009). It has been demonstrated that GPx and CAT These enzymes-play a crucial role as the first line of the

344 antioxidant defense system against ROS generated during oxidative stress (Ray \& Husain, 
2002). GPx catalyses reduction of $\mathrm{H}_{2} \mathrm{O}_{2}$-or other peroxides at the expense of GSH oxidation to

exidized glutathione, and CAT converts $\mathrm{H}_{2} \mathrm{O}_{2}$ to $\mathrm{H}_{2} \mathrm{O}$. Both enzyme activities are thus essential for the intracellular quenching of cell-damaging peroxide species but by two distinct mechanisms, since GPX is a glutathione related enzyme whereas CAT is independent from glutathione (Goya, Martin, Ramos, Mateos, \& Bravo, 2009). However, a rapid return of the antioxidant enzyme activities to basal values once the challenge has been surmounted will place the cell in a favorable condition to deal with a new insult. Therefore, changes in their activity are considered as biomarkers of the antioxidant cellular response. In non-stressed HepG2 cells, lunasin did not provoke any change in the activity of GPX and CAT (data not shown). These results indicate that in spite of the direct effects of lunasin on ROS levels and GSH content, the defence enzymatic system in the cells was balanced. The increase in the activity of GPx and CAT observed after exposure to $t \mathrm{BOOH}$ (Figure $3 \mathrm{~A}$ and $3 \mathrm{~B}$ ), clearly indicates a positive response of the cell defense system to face the increasing generation of ROS evoked by the oxidative insult (Alía et al., 2006; Goya et al., 2009). However, a rapid return of the antioxidant enzyme activities to basal values once the challenge has been surmounted will place the cell in a favorable condition to deal with a new insult. It has been previously shown that flavonoid quercetin (Alía et al., 2006), olive oil phenol hydroxytyrosol (Goya et al., 2007), organic selenium derivatives (Cuello et al., 2007), and seaweed metabolite phloroglucinol (Quéguineur et al., 2012), among others, protect HepG2 cell 364 integrity by preventing the severely increased activity of antioxidant enzymes induced by $t$ $365 \mathrm{BOOH}$. In the present study, we show, for the first time, that a $20 \mathrm{~h}$ treatment of human 366 HepG2 cells with lunasin prevents the permanent increase in the activity of both glutathionerelated GPx and glutathione-independent CAT induced by oxidative stress (Figure 3A and 3B). Thus, the restrained ROS production during the stressful challenge in lunasin-treated 
potential direct effect of lunasin on antioxidant enzymes gene expression throughout the

371 antioxidant response element cannot be ruled out, the protective mechanism of lunasin can be

372 illustrated in terms of regulation of the specific activity of antioxidant defence enzymes.

\subsection{Lunasin-induced reduction of protein oxidation}

Since protein carbonyl concentration has been found elevated in various diseases thought to be related to free radical damage, it has been widely used as an index of protein oxidation in biological and medical sciences (Mateos, \& Bravo, 2007). Figure 4A shows that 3 htreatment of HepG2 with $400 \mu \mathrm{M} t$-BOOH evoked a significant increase in the cellular concentration of protein carbonyl groups of about 3-times compared to non-stressed cells, indicating an intense oxidative damage to cell proteins. However, pre-incubation of the cells with lunasin at concentrations ranged from 0.5 to $10 \mu \mathrm{M}$ for $20 \mathrm{~h}$ reduced the protein carbonyl levels down to levels measured in non-stressed cells. This fact indicates the ability of this peptide to diminish the level of protein oxidation resulting from chemical induction with $t$ BOOH. Other food compounds including plant polyphenols, beta carotene, lutein, seaweed metabolite phloroglucinol and biscuit melanoidins have been also reported to prevent protein

386 oxidation (Alía et al., 2006; Goya et al., 2007; Martín, Ramos, Mateos, Izquierdo-Pulido, Bravo, \& Goya, 2010; Murakami, Hirakawa, Inui, Nakano, \& Yoshida, 2002; Quéguineur et al., 2012). However, to date, no dietary peptide had demonstrated to exert this protective 389 effect.

\subsection{Lunasin prevents apoptosis by reducing stress-induced caspase-3}

Oxidative stress-induced hepatic cell injury results not only from direct chemical interactions by altering cellular macromolecules such as DNA, proteins and lipids, but also

394 from alterations in key mediators of stress signals and stress-dependent apoptosis reactions 
395 (Singh, \& Czaja, 2008). In this regard, ROS generation has been described as a critical upstream activator of the caspase cascade that ends up with stimulation of downstream key effectors such as caspase-3 and subsequent development of apoptosis (Singh, \& Czaja, 2008). Besides, GSH depletion is a common feature of apoptotic cells, and its role as a critical regulator in the signaling pathways leading to the progression of apoptosis has been reported 400 (Franco, \& Cidlowski, 2009, 2012). As shown in Figure 4B, the caspase-3 activity was significantly increased after $400 \mu \mathrm{M} t$-BOOH treatment for $3 \mathrm{~h}(P<0.001)$, compared with the non-stressed cells. Previous studies had also demonstrated this pro-apoptotic effect of chemical $t$ - $\mathrm{BOOH}$ on HepG2 cells through activation of caspase- 3 and, ultimately, cell death 404 (Martín, Granado-Serrano, Ramos, Izquierdo-Pulido, Bravo, \& Goya, 2010). Consistent with the above mentioned ROS scavenging effect of lunasin, this peptide in the range of 1-10 $\mu \mathrm{M}$

406

407

effectively reduced caspase-3 activity in $t$-BOOH-induced HepG2 cells $(P<0.001)$ although no dose-response was observed, indicating that increases in lunasin's concentration did not improved the caspase- 3 activity reduction caused by this peptide. The demonstrated effects indicated the preventive capacity of lunasin against preventing the-apoptotic effects induced by disruption of the redox steady-state.

\subsection{Stability of peptide lunasin in HepG2 cultures}

In order to study the stability of lunasin after its addition to HepG2 cells and incubation for $20 \mathrm{~h}$, the medium without and with lunasin $(10 \mu \mathrm{M})$ at different incubation hours $(0,2,6$, 12, and $20 \mathrm{~h}$ ) was analyzed by HPLC-MS/MS. As an example, Figure 5 shows the extracted ion chromatograms of the molecular ion of lunasin $\mathrm{m} / \mathrm{z} 1257.5$ (charge +4 ) obtained after 6 , 12, and 20 h-incubation of cells with lunasin. The lunasin's peak area was measured (Figure 6), and it was observed that the content of this peptide in the medium notably decreased with the incubation time. After 12 h-incubation, only $29 \%$ of initial lunasin remained in the 
medium, and after $20 \mathrm{~h}$, less than $1 \%$ was visibleobservable. In the present study, the analysis by HPLC-MS/MS also allowed the identification of lunasin-derived fragments that could be released during incubation of lunasin with HepG2 cells (Figure 5). Five lunasin-fragments were observed; all of them corresponding to the C-terminal region of the peptide, from the amino acid residue 25 . The identified peptides' peak areas were also measured (Figure 6). After 2 h-incubation, fragments $f(25-43)$ and $f(26-43)$ were already visibledetectable in the medium. Other three peptides were released at 6 and $12 \mathrm{~h}$-incubation. It has to be highlighted that after $20 \mathrm{~h}$, extracellular lunasin only represented the $0.6 \%$ of total identified peptides whereas peptide $f(25-43)$ represented $76.5 \%$. Therefore, it can be postulated that the most abundant fragment, $\mathrm{f}(25-43)$, can be, at least, in part, responsible of the activity observed, and

430 further studies with this lunasin-derived peptide are already in progress. In spite the important hydrolysis observed, it cannot be excluded that part of the lunasin could also internalize into HepG2 cells. It is also important to note that all the identified fragments contain the Cterminal part of the lunasin, which had previously been proposed as the active site of lunasin (Hernández-Ledesma et al., 2013). The hydrolysis of lunasin observed in contact with the HepG2 cells was different to that observed in our previous study with differentiated human intestinal Caco-2 cells (García-Nebot et al., 2014), where most of lunasin added to culture medium remained intact after $24 \mathrm{~h}$ incubation with these cells.

In the present study, analyses, focused on evaluating the antioxidant activity of peptide lunasin in HepG2 cells, were carried out after $20 \mathrm{~h}$ pre-treatment with this peptide. It was

440 demonstrated the protective mechanism on cells submitted to an oxidative stress that can be 441 illustrated in terms of regulation of the cellular redox status, i.e. peptide treatment restrained 442 ROS production and maintained GSH concentration during the stress which reduced the 443 necessity of peroxide detoxification through GPx and CAT. Additionally, a controlled ROS 444 generation reduced oxidative damage to proteins and restrained activity of the apoptotic 
pathway resulting in improved cell viability. The final findings found on lunasin's stability in

446 HepG2 cells indicated that this peptide was markedly hydrolyzed at the selected time $(20 \mathrm{~h})$,

447 and thus, in addition to the remaining peptide, the fragments released during its hydrolysis

448 might be the actual responsible for the observed effects. All the peptides identified at $20 \mathrm{~h}$

449 corresponded to the active site-sequence of lunasin described to date. Also, they contained the

450 motif RGD known to be crucial for the interaction of proteins or peptides with its cell surface

451 receptor (Ruoslahti, \& Pierschbacher, 1986). Therefore, these structural characteristics make

452 these five peptides promising chemo-protective peptides against oxidative stress in liver

453 HepG2 cells. In conclusion, our results point out for the first time a direct antioxidant action

454 of lunasin or its derived fragments on hepatocytes exposed to oxidizing species. It indicates

455 the possibility that these peptides may significantly contribute to preserve the integrity of liver

456 tissues against oxidative damage related disorders. Since this study has been carried out with

457 synthetic lunasin which secondary and tertiary structure could differ to that of plant-purified

458 lunasin, confirmation of the effects should be needed to demonstrate the chemo-protective

459 potential of natural lunasin.

\section{ACKNOWLEDGMENTS}

This work was supported by projects AGL2010-17579, AGL2011-24643, CSD2007-

00063 from Programa Consolider-Ingenio from the Spanish Ministry of Education and

Science (CICYT), FEDER-INNTERCONECTA-GALICIA (ENVELLEFUN), and FP7-

465 SME-2012-315349. The authors are participants in the FA1005 COST Action INFOGEST on

466 food digestion. I. C. -H. and S. F. -T. acknowledge Ministry of Economy and

467 Competitiveness (MINECO) for their FPI fellowships, and B. H. -L. acknowledges MINECO

468 for her "Ramón y Cajal" contract. 
$470 \quad$ Conflict of interests

471 The authors declare no competing financial interest.

472 
474 - Alía, M., Ramos, S., Mateos, R., Bravo, L., \& Goya, L. (2005). Response of the antioxidant 475 defence system to tert-butyl hydroperoxide and hydrogen peroxide in a human hepatoma cell 476 line (HepG2). Journal of Biochemical and Molecular Toxicology, 19, 119-128.

477 - Alía, M., Ramos, S., Mateos, R., Bravo, L., \& Goya, L. (2006). Quercetin protects human 478 hepatoma cell line (HepG2) against oxidative stress induced by tertbutyl hydroperoxide. 479 Toxicology and Applied Pharmacology, 212, 110-118.

480 - Cam, A., Sivaguru, M., \& González de Mejia, E. (2013). Endocytic mechanism of 481 internalization of dietary peptide lunasin into macrophages in inflammatory condition 482 associated with cardiovascular disease. PLoS One, 8, e72115.

483 - Contreras, M. M., Gómez-Sala, B., Martín-Álvarez, P., Amigo, L., Ramos, M., \& Recio, I. 484 (2010). Monitoring the large-scale production of the antihypertensive peptides RYLGY and 485 AYFYPEL by HPLC-MS. Analytical and Bioanalytical Chemistry, 397, 2825-2832.

486 - Cuello, S., Ramos, S., Mateos, R., Martín, M. A., Madrid, Y., Cámara, C., Bravo, L., \& 487 Goya, L. (2007). Selenium methylselenocysteine protects human hepatoma HepG2 cells 488 against oxidative stress induced by tert-butylhydroperoxide. Analytical and Bioanalytical 489 Chemistry, 389, 2167-2178.

490 - Dia, V. P., Torres, S., de Lumen, B. O., Erdman, J. W., \& González de Mejía, E. (2009). 491 Presence of lunasin in plasma of men alter soy protein consumption. Journal of Agricultural 492 and Food Chemistry, 57, 1260-1266.

493 - FDA Talk Paper. (1999). FDA approves new health claim for soy protein and coronary heart 494 disease. FDA, United States Department of Health and Human Services, October 26, 1999. 495 Washington, DC: United States Government Printing Office. 
496 - Federico, A., Morgillo, F., Tuccillo, C., Clardiello, F., \& Loguercio, C. (2007). Chronic

497 inflammation and oxidative stress in human carcinogenesis. International Journal of Cancer, $498 \quad 121,2381-2386$.

499 - Franco, R., \& Cidlowski, J. A. (2009). Apoptosis and glutathione: beyond an antioxidant. 500 Cell Death and Differentiation, 16, 1303-1314.

501 - Franco, R., \& Cidlowski, J. A. (2012). Glutathione efflux and cell death. Antioxidant and 502 Redox Signalling, 17, 1694-1713.

503 - Gálvez, A. F. (2012). Abstract 10693: Identification of lunasin as the active component in 504 soy protein responsible for reducing LDL cholesterol and risk of cardiovascular disease. 505 Circulation, 126, A10693.

506 - García-Nebot, M. J., Recio, I., \& Hernández-Ledesma, B. (2014). Antioxidant activity and 507 protective effects of peptide lunasin against oxidative stress in intestinal Caco-2 cells. Food 508 Chemical and Toxicology, 65, 155-161.

509 - González de Mejía, E., \& Dia, V. P. (2009). Lunasin and lunasin-like peptide inhibit 510 inflammation through supression of NFkB pathway in the macrophage. Peptides, 30, 23885112398.

512 - Goya, L., Martín, M. A., Ramos, S., Mateos, R., \& Bravo, L. (2009). A cell culture model 513 for the assessment of the chemopreventive potential of antioxidant compounds". Current $514 \quad$ Nutrition and Food Science, 5, 56-64.

515 - Goya, L., Mateos, R., \& Bravo, L. (2007). Effect of the olive oil phenol hydroxytyrosol on 516 human hepatoma HepG2 cells. Protection against oxidative stress induced by tert517 butylhydroperoxide. European Journal of Nutrition, 46, 70-78.

518 - Granado-Serrano, A. B., Martín, M. A., Izquierdo-Pulido, M., Goya, L., Bravo, L., \& 519 Ramos, S. (2007). Molecular mechanisms of (-)-epicatechin and chlorogenic acid on the 
regulation of the apoptotic and survival/proliferation pathways in a human hepatoma cell line (HepG2). Journal of Agricultural and Food Chemistry, 55, 2020-2027.

- Hernández-Ledesma, B., de Lumen, B. O., \& Hsieh, C. -C. (2013). 1997-2012: Fifteen years food peptides in health and disease (23-44). Rijeka, Croatia: InTech-Open Access Publisher.

- Hernández-Ledesma, B., Hsieh, C. -C., \& de Lumen, B. O. (2009a). Antioxidant and antiinflammatory properties of cancer preventive peptide lunasin in RAW 264.7 macrophages. Biochemical and Biophysical Research Communications, 390, 803-808.

- Hernández-Ledesma, B., Hsieh, C. -C., \& de Lumen, B. O. (2009b). Lunasin and BowmanBirk protease inhibitor (BBI) in US commercial soy foods. Food Chemistry, 115, 574-580.

- Hernández-Ledesma, B., Hsieh, C. -C., \& de Lumen, B. O. (2013). Chemopreventive 531 properties of peptide lunasin: a review. Protein \& Peptide Letters, 20, 424-432.

- Herrera, B., Fernández, M., Alvarez, A., Roncero, C., Benito, M., Gil, J., \& Fabregat, I. (2001). Activation of caspases occurs downstream from radical oxygen species production, Bcl-xL down-regulation, and early cytochrome $\mathrm{C}$ release in apoptosis induced by 535 transforming growth factor beta in rat fetal hepatocytes. Hepatology, 34, 548-556.

536 - Hsieh, C. -C., Hernández-Ledesma, B., Jeong, H. J., Park, J. H., \& de Lumen, B. O. (2010). 537 Complementary roles in cancer prevention: protease inhibitor makes the cancer preventive 538 peptide lunasin bioavailable. PLoS ONE, 5, e8890. Jaeschke, H., Gores, G. J., Cederbaum, A. I., Hinsen, J. A., Pessayre, D., \& Lemasters, J. J. (2002). Mechanism of hepatotoxicity. Toxicological Sciences, 65, 166-176.

541 - Jeong, H. J., Lee, J. R., Jeong, J. B., Park, J. H., Cheong, Y. K., \& de Lumen, B. O. (2009). 542 The cancer preventive seed peptide lunasin from rye is bioavailable and bioactive. Nutrition and Cancer, 61, 680-686. 
544 - Jeong, J. B., de Lumen, B. O., \& Jeong, H. J. (2010). Lunasin peptide purified from

545 Solanum nigrum L. protects DNA from oxidative damage from suppressing the generation of 546 hydroxyl radical via blocking Fenton reaction. Cancer Letters, 293, 58-64.

547 - Mari, M., Morales, A., Colell, A., García-Ruiz, C., \& Fernández-Checa, J. C. (2009). 548 Mitochondrial glutathione, a key survival antioxidant. Antioxidants \& Redox Signalling, 11, $549 \quad 2685-2700$.

550 - Martín, M. A., Granado-Serrano, A. B., Ramos, S., Izquierdo-Pulido, M., Bravo, L., \& 551 Goya, L. (2010). Cocoa flavonoids up-regulate antioxidant enzymes activity via ERK1/2 552 pathway to protect against oxidative stress-induced apoptosis in HepG2 cells. Journal of 553 Nutritional Biochemistry, 21, 196-205.

554 - Martín, M. A., Ramos, S., Mateos, R., Izquierdo-Pulido, M., Bravo, L., \& Goya, L. (2010). 555 Protection of human HepG2 cells against oxidative stress induced by the flavonoid 556 epicatechin. Phytotherapy Research, 24, 503-509.

557 - Mateos, R., \& Bravo, L. (2007). Chromatographic and electrophoretic methods for the 558 analysis of biomarkers of oxidative damage to macromolecules (DNA, lipids, and proteins). 559 Journal of Separation Science, 30, 175-191.

560 - Mateos, R., Goya, L., \& Bravo, L. (2006). Uptake and metabolism of hydroxycinnamic 561 acids (chlorogenic, caffeic and ferulic acids) by HepG2 cells as a model of human liver. 562 Journal of Agricultural and Food Chemistry, 54, 8724-8732.

563 - Meisel, H. (2004). Multifunctional peptides encrypted in milk proteins. BioFactors, 21, 5556461.

565 - Mersch-Sundermann, V., Knasmuller, S., Wu, X. J., Darroudi, F., \& Kassie, F. (2004). Use 566 of a human-derived liver cell line for the detection of cytoprotective, antigenotoxic and 567 cogenotoxic agents. Toxicology, 198, 329-340. 
- Murakami, C., Hirakawa, Y., Inui, H., Nakano, Y., \& Yoshida, H. (2002). Effects of

569 epigallocatechin 3-O-gallate on cellular antioxidative system in HepG2 cells. Journal of $570 \quad$ Nutritional Science and Vitaminology, 48, 89-94.

571 - Quéguineur, B., Goya, L., Ramos, S., Martín, M. A., Mateos, R., \& Bravo, L. (2012).

572 Phloroglucinol: Antioxidant properties and effects on celular oxidative markers in human

573 HepG2 cell line. Food Chemical and Toxicology, 50, 2886-2893.

574 - Ramos, S. (2008). Cancer chemoprevention and chemotherapy: dietary polyphenols and 575 signalling pathways. Molecular Nutrition and Food Research, 52, 507-526.

576 - Ray, G., \& Husain, S. A. (2002). Oxidants, antioxidants and carcinogenesis. Indian Journal 577 of Experimental Biology, 40, 1213-1232.

578 - Richert, S., Wehr, N. B., Stadtman, E. R., \& Levine, R. L. (2002). Assessment of skin 579 carbonyl content as a noninvasive measure of biological age. Archives of Biochemistry and 580 Biophysics, 397, 430-432.

581 - Ruoslahti, E., \& Pierschbacher, M. D. (1986). Arg-Gly-Asp: A versatile cell recognition 582 signal. Cell, 44, 517-518.

583 - Singh, R., \& Czaja, M. J. (2008). Regulation of hepatocyte apoptosis by oxidative stress. 584 Journal of Gastroenterology \& Hepatology, 23, 501-502.

585 - Vitaglione, P., Morisco, F., Caporaso, N., \& Fogliano, V. (2004). Dietary antioxidant 586 compounds and liver health. Critical Reviews in Food Science and Nutrition, 44, 575-86. 


\section{FIGURE CAPTIONS}

589 Figure 1. Direct and protective effects of peptide lunasin on cell viability and intracellular 590 ROS and GSH levels. HepG2 cells were pre-incubated with medium or medium 591 supplemented with lunasin (final concentration ranged from 0.5 to $10 \mu \mathrm{M}$ ) for $20 \mathrm{~h}$ before 592 treatment with medium ( $\square$ : non-stressed cells) or medium supplemented with $400 \mu \mathrm{M} t$ $593 \mathrm{BOOH}$ for $3 \mathrm{~h}(\mathbf{\square})$. (A) Cell viability was measured by the CV assay. Results are expressed as 594 percent of viable cells, $n=12$. (B) Intracellular ROS generation. Fluorescence units 595 corresponding to intracellular ROS production are expressed as percent of data from non596 stressed cells, $n=8$. (C) Intracellular GSH levels. Results of fluorescent analysis are 597 calculated as nmoles of GSH per mg of protein, and represented as percentage of non-stressed 598 cells, $n=6 .{ }^{*}(P<0.05),{ }^{* * *}(P<0.001)$, significantly different from control non-stressed cells, 599

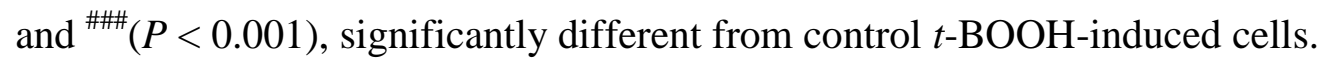

600

601 Figure 2. Morphological analysis of HepG2 cells. HepG2 cells were pre-incubated with 602 medium or medium supplemented with lunasin (final concentration $0.5-10 \mu \mathrm{M}$ ) for $20 \mathrm{~h}$ 603 before treatment with medium (non-stressed cells) or medium supplemented with $400 \mu \mathrm{M} t$ 604 BOOH for $3 \mathrm{~h}$. Representative images of (A) non-stressed cells pre-incubated with medium, 605 (B) $t$-BOOH-induced cells pre-incubated with medium, and $t$-BOOH-induced cells pre606 incubated with (C) $0.5 \mu \mathrm{M}$ lunasin and (D) $5 \mu \mathrm{M}$ lunasin. HepG2 cells pre-incubated with 607 medium and treated with $t$-BOOH showed reduction in cell numbers and loss of cell-to-cell 608 contact (arrows), compared with non-stressed cells pre-incubated with medium, and $t$-BOOH609 induced cells pre-incubated with lunasin. Size bar: $10 \mu \mathrm{m}$.

611 Figure 3. Protective effects of lunasin on enzymes GPx and CAT activity. HepG2 cells were pre-incubated with medium or medium supplemented with lunasin (final concentration ranged 
613 from 0.5 to $10 \mu \mathrm{M})$ for $20 \mathrm{~h}$ before oxidation induction with $400 \mu \mathrm{M} t$-BOOH for $3 \mathrm{~h}(\mathbf{\square})$.

614 Results of enzymes (A) GPx and (B) CAT activities are calculated as mUnits per mg of 615 protein and represented as percentage of data from non-stressed cells ( $\square$ ). Represented values 616 are means $\pm \mathrm{SD}$ of $n=6(\mathrm{GPx})$ and $n=4(\mathrm{CAT}){ }^{* * *}(P<0.001)$, significantly different from 617 control non-stressed cells, and ${ }^{\#}(P<0.05),{ }^{\# \#}(P<0.01),{ }^{\# \#}(P<0.001)$, significantly different 618 from control $t$-BOOH-induced cells.

619

620 Figure 4. Protective effects of lunasin on protein carbonyl content and caspase-3 activity. 621 HepG2 cells were pre-incubated with medium or medium supplemented with lunasin (final 622 concentration ranged from 0.5 to $10 \mu \mathrm{M}$ ) for $20 \mathrm{~h}$ before oxidation induction with $400 \mu \mathrm{M} t$ $623 \mathrm{BOOH}$ for $3 \mathrm{~h}(\mathbf{m})$. (A) Protein carbonyl content. Results are expressed as nmol per mg 624 protein and represented as percentage of non-stressed cells ( $\square$ ). (B) Caspase-3 activity. 625 Results are calculated as Units per $\mu \mathrm{g}$ of protein and expressed as percent of control data. 626 Values are means \pm SD of 4 different samples per condition. ${ }^{* * *}(P<0.001)$, significantly

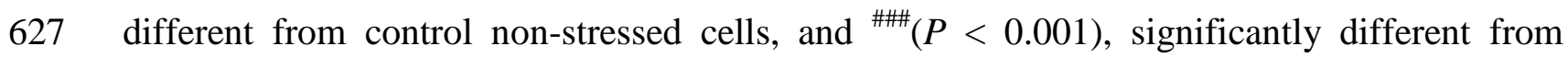
628 control $t$-BOOH-induced cells.

630 Figure 5. Stability of peptide lunasin in medium added to HepG2 cells. (A) Extracted ion 631 chromatogram (EIC) of the molecular ion of lunasin (F1) $m / z$ 1257.5 (charge +4$), f(32-43)$ $632(\mathrm{~F} 2) \mathrm{m} / \mathrm{z}, 1324.5($ charge +1), f(30-43) (F3) $\mathrm{m} / \mathrm{z}, 1565.5($ charge +1), f(29-43) (F4) $\mathrm{m} / \mathrm{z}, 1693.8$ 633 (charge +1), f(26-43) (F5) $\mathrm{m} / \mathrm{z} 1034.1($ charge +2), f(25-43) (F6) $\mathrm{m} / \mathrm{z} 1102.7($ charge +2$)$ in 634 serum free DMEM-F12 medium incubated with $10 \mu \mathrm{M}$ lunasin and collected after $(\mathrm{A})-6 \mathrm{~h}$, 635 (B)-12 h, and (C)-20 h-incubation._Figure 6. 636 lunasin (F1) and its derived fragments (F2-F6) in serum free DMEM-F12 medium incubated 637 with lunasin for $0,2,6,12$, and $20 \mathrm{~h}$. 